\title{
Psychological Aspects of Enuresis in Childhood
}

\author{
Timothy P Lefeber*, Olivia E Nield and Linda S Nield \\ West Virginia University School of Medicine, USA
}

*Corresponding author: Timothy P Lefeber, Assistant Professor of Pediatrics, West

Virginia University School of Medicine, Morgantown, USA.

Received Date: November 22, 2018

Published Date: December 18, 2018

\section{Introduction}

Since approximately $10-15 \%$ of all children at age six years will have primary monosymptomatic nocturnal enuresis (PMNE) [1], it is a common problem that presents to the general pediatrician and often referred to the urologist or nephrologist. PMNE is defined as bedwetting in children older than age five years without lower urinary tract symptoms or bladder dysfunction [2], and each year $15 \%$ of children will outgrow the condition resulting in approximately $1 \%$ to $2 \%$ of adolescents still suffering from the condition. Nearly all studies addressing PMNE reveal a strong genetic predisposition at rates of familial history as high as $75 \%$ [3]. Since the 1990's, the medical literature has become replete with studies which focus on the psychological, psychosocial, and quality of life issues that are associated with enuresis. Research provides convincing evidence that enuresis is associated with long lasting effects that persist beyond childhood into adolescence and adulthood. Although time constraints can often lead to the inadequate addressing of psychological effects, it is prudent to consider expanding patient visits so time is available to screen for these life-altering concerns. A brief up-to-date literature review of the psychological aspects of enuresis along with suggested behavioral screening tools are provided for clinicians who care for patients with PMNE.

\section{Psychiatric and Behavioral Associations}

In population studies, it has been found that children with enuresis have a rate of behavioral and emotional disorders at 20 $30 \%[4,5]$ which is two to three times higher than in children without enuresis. The most strongly associated condition with enuresis is attention deficit hyperactivity disorder (ADHD). An inhibitory control defect is believed to be at the center of the etiology of both ADHD and PMNE. In PMNE, it is postulated that during sleep, an inability to inhibit the micturition reflex coupled with the inability to awaken leads to bedwetting [6]. Baeyens and colleagues report comorbid ADHD and enuresis rates at $28.3 \%$, versus $10.3 \%$ in the general community [7]. Incidence remains higher in males with PMNE, and the subtype is more often inattentive than hyperactive
[8]. The rates of comorbid disorders are increased in subjects who are older, male, and of lower socioeconomic status, amongst other factors [9]. Although studies have not proven causation or a genetic link, Equit et al found specific differences in the processing of emotions in children with enuresis, and the most intense reactions were displayed by children with PMNE and ADHD [10]. More intense reactions from the child could promote negative reactions from peers and parents, which in turn could contribute to the low self-esteem or self-concept experienced by children with enuresis [10].

In addition to supporting associations between enuresis and ADHD, Gulisano et al reported associations between enuresis and other neuropsychiatric conditions. Oppositional defiant disorder, conduct disorder, obsessive compulsive disorder and tics occur at higher rates in enuretics when compared to continent controls [11-13]. Administering the Child Behavior Checklist (CBCL) to their subjects [14], Gulisano et al. [13] revealed that the enuresis group demonstrated significantly higher total CBCL scores and higher sub-scores for negative components such as somatic complaints, being anxious/depressed, and attention problems compared to healthy controls.

\section{Developmental and Neurobiological Associations}

Development of skills across nearly all domains of early childhood may differ in children with enuresis compared to unaffected children. Esposito et al found that enuretic children in their study had a significantly higher incidence of neurologic deficits in areas such as fine and gross motor skills, spatial and visuomotor perception, speech and coordination [15]. Research incorporating central nervous system imaging has revealed a potential link between enuresis and observed brain abnormalities which could result in motor and sensory deficits [16]. These findings remain controversial with regards to PMNE. Joinson and co-authors found that developmental delay was related to daytime wetting or diurnal wetting, but not night time wetting [17]. 
Having a difficult temperament at 24 months of age has been reported to be associated with bedwetting at four to nine years of age [18]. Conduct problems, hyperactivity, and less pro-social behavior at 42 months of age have also been found to be associated with subsequent bedwetting. Data reveals that the more severe the symptoms, the higher the frequency and persistence of bedwetting [18]. Stressful life events in childhood have been suspected contributors to the development of psychological maladies that could impact bladder control [19]. The proposed mechanism is as follows: stress leads to increased cortisol secretion, causing a negative feedback loop that suppresses antidiuretic hormone, which has been found to be deficient in children with bedwetting $[20,21]$. In comparison to other forms of incontinence, there is a paucity of evidence to support this mechanism in regards to PMNE [19].

\section{Long-Term Effects}

Although it is difficult to tease out the causative relationships between comorbid conditions and early childhood events, there is minimal debate that enuresis has long-term consequences. Patients with PMNE may be able to hide their condition from peers, but the psychosocial consequences remain prominent. School trips, sleepovers, and other overnight activities are limited by the fear of bedwetting. Adolescents and adults who continue to wet the bed may suffer from depression and low self-esteem, along with experiencing less educational achievement and disrupted work and social lives [23]. In children who attain nighttime continence at a later age, there is evidence of a higher risk of behavioral health issues. Results of a prospective study found children had more mental health disorders at ages 11 and 13 years if their bedwetting resolved by age 11 years compared to those whose bedwetting resolved by age 9 years [4]. Bedwetting at 14 years of age was associated with negative self-image and depressive symptoms in girls [24].

\section{Treatment and Improved Quality of Life}

When care is sought, primary care providers and specialists are charged with effectively treating PMNE as the psychological consequences will negatively affect patients and may have long term consequences. The efficacy of alarms and desmopressin for the treatment of enuresis has been established in Cochrane Reviews $[25,26]$. Along with the resolution of bedwetting, improvement in behavioral problems [27] and quality of life scores [27-29] have been associated with the implementation of effective enuresis interventions. The literature provides reassurance that effective treatment of PMNE can improve quality of life, and this reassurance should be passed along to the patient. As part of the treatment regimen, referral to behavioral medicine specialists may be necessary to address the entire spectrum of potential psychological conditions that could accompany PMNE. The Table 1 provides a list of behavioral screening tools. Clinicians are encouraged to become familiar with these resources to determine which screening tool can be most practically administered in one's specific practice setting. Scheduling adequate time for patient appointments to include this screening process is prudent to allow for a most effective physicianpatient encounter. When screening tools reveal possible behavioral or psychiatric pathology, appropriate referrals to behavioral specialists should be prescribed.

Table 1: Behavioral Screening Tools for Children.

\begin{tabular}{|c|}
\hline General Behavioral Screening Tools \\
\hline Child Behavioral Checklist (CBCL) ${ }^{a}$ \\
\hline Child Depression Inventory (CDI) ${ }^{\mathrm{b}}$ \\
\hline Children's Yale-Brown Obsessive Compulsive Scale (CYBOCS) ${ }^{c}$ \\
\hline Conners' Parent-Teacher Rating Scaled \\
\hline Multidimensional Anxiety Scale for Children (MASC) ${ }^{\mathrm{e}}$ \\
\hline $\begin{array}{l}\text { National Institute for Children's Health Quality Vanderbilt Assessment } \\
\qquad \text { Scales }^{f}\end{array}$ \\
\hline Patient Health Questionnaire (PHQ-9/PHQ-2) ${ }^{\mathrm{g}}$ \\
\hline Screen for Child Related Anxiety Disorders (SCARED) ${ }^{\mathrm{h}}$ \\
\hline Additional Screening Tools for Children with Enuresis \\
\hline Dysfunctional Voiding and Incontinence Scoring System (DVISS) ${ }^{\mathrm{i}}$ \\
\hline Dysfunctional Voiding Symptom Score (DVSS) ${ }^{i}$ \\
\hline Incontinence Symptoms Index-Pediatric (ISI-P) ${ }^{\mathrm{k}}$ \\
\hline Pediatric Urinary Incontinence Quality of Life (PINQ) ${ }^{1}$ \\
\hline
\end{tabular}

a. Achenbach TN (1990) Manual for the child behavior checklist/4e18 and 1991 profile. Burlington, VT: University of Vermont, USA.

b. Kovacs M (1988) Children's depression inventory (CDI). (Italian edn), Organizzazioni Speciali, Florence, USA.

c. Scahill L, Riddle MA, McSwiggin-Hardin M, Ort SI, King RA, et al. (1997) Children's Yale- Brown Obsessive Compulsive Scale: reliability and validity. J Am Psychiatry 36: 844-852.

d. Conners K. Conners (1978) parents and teacher rating scales. Psychological Corporation, San Antonio, USA.

e. March JS, Parker JD, Sullivan K, Stallings P, Conners CK (1997) The multidimensional anxiety scale for children: factor structure, reliability, and validity. J Am Acad Child Adolesc Psychiatry 36: 554-565.

f. https://www.nichq.org/sites/default/files/resource-file/ NICHQ-Vanderbilt-Assessment-Scales.pdf

g. $\quad$ Spitzer RL, Kroenke K, Williams JBW (1999) Patient Health Questionnaire Study Group. Validity and utility of a self-report version of PRIME-MD: the PHQ Primary Care Study. JAMA 282: 1737-1744.

h. Birmaher B, Brent DA, Chiappetta L, Bridge J, Monga S, et al. (1999) Psychometric properties of the Screen for Child Anxiety Related Emotional Disorders (SCARED): A replication study. J Am Acad Child Adolesc Psychiatry 38(10): 1230-1236.

i. Akbal C, Genc Y, Burgu B, Ozden E, Tekgul S (2005) Dysfunctional voiding and incontinence scoring system: quantitative evaluation of incontinence symptoms in pediatric population. J Urol 173(3): 969973.

j. Farhat W, Bägli DJ, Capolicchio G, O'Reilly S, Merguerian PA, et al. (2000) The dysfunctional voiding scoring system: quantitative standardization of dysfunctional voiding symptoms in children. J Urol 164(3 Pt 2): 1011-1015.

k. Nelson CP, Park JM, Bloom DA, Wan J, Dunn RL, et al. (2007) Incontinence Symptom Index-Pediatric: development and initial validation of a urinary incontinence instrument for the older pediatric population. J Urol 178(4 Pt 2): 1763-1767.

l. Bower W, Sit F, Bluyssen N, Wong E, Yeung CK (2006) PINQ: a valid, reliable and reproducible quality-of-life measure in children with bladder dysfunction. J Pediatr Urol 2(3): 185-189.

\section{Conclusion}

The primary care provider, the urologist and nephrologist frequently care for patients with PMNE, and they must be aware 
of the potential accompanying psychological conditions. Screening for and addressing these comorbid psychological conditions and psychosocial consequences of PMNE is imperative. Biopsychosocial influences in early childhood may influence the trajectory of this predominantly genetic condition to an unknown degree. Behavioral medicine support should be employed, and reassurance should be provided to the affected patients as effective treatments for PMNE are available, and improvements in quality of life can follow.

\section{Acknowledgement}

None.

\section{Conflict of Interest}

No Conflict of interest.

\section{References}

1. Vande Walle J, Rittig S, Bauer S, Eggert P, Marschall-Kehrel D, et al (2012) Practical consensus guidelines for the management of enuresis. Eur J Pediatr 171(6): 971-983.

2. Austin PF, Bauer S, Bower W, Chase J, Franco I, et al. (2014) The standardization of terminology of bladder function in children and adolescents: update report from the standardization committee of the International Children's Continence Society (ICCS). J Urol.

3. Wei CC, Wan L, Lin WY, Tsai FJ (2010) Rs 6313 polymorphism in 5-hydroxytryptamine receptor $2 \mathrm{~A}$ gene association with polysymptomatic primary nocturnal enuresis. J Clin Lab Anal 24(6): $371 \mathrm{e} 5$.

4. Feehan M, McGee R, Stanton W (1990) 6 year follow-up of childhood enuresis: prevalence in adolescence and consequences for mental health. J Paediatr Child Health 26(2): 75-79.

5. Van Herzeele C, De Bruyne P, De Bruyne E, Walle JV (2015) Challenging factors for enuresis treatment: psychological problems and nonadherence. J Pediatr Urol 11(6): 308-313.

6. Von Gontard A, Equit M (2015) Comorbidity of ADHD and incontinence in children. Eur Child Adolesc Psychiatry 24(2): 127-140.

7. Baeyens D, Roeyers H, D'Haese L (2006) The prevalence of ADHD in children with enuresis: comparison between a tertiary and non-tertiary care sample. Acta Paediatr 95(3): 347-352.

8. Baeyens D, Roeyers H, Hoebeke P, Antrop I, Mauel R, et al. (2006) The impact of attention deficit hyperactivity disorders on brainstem dysfunction in nocturnal enuresis. J Urol 176(2): 744-748.

9. Baeyens D, Roeyers H, Vande Walle J (2005) Behavioural problems and attention-deficit hyperactivity disorder in children with enuresis: a literature review. Eur J Pediatr 164(11): 665-672.

10. Equit M, Becker A, El Khatib D, Rubly M, Becker N, et al. (2014) Central nervous system processing of emotions in children with nocturnal enuresis and attention-deficit/hyperactivity disorder. Acta Paediatr 103(8): 868-878.

11. Niemczyk J, Equit M, Braun-Bither K, Klein AM, von Gontard A (2015) Prevalence of incontinence, attention deficit/hyperactivity disorder and oppositional defiant disorder in preschool children. Eur Child Adolesc Psychiatry 24: 837-843.

12. Park S, Kim BN, Kim JW, Hong SB, Shin MS, et al. (2013) Nocturnal enuresis is associated with attention deficit hyperactivity disorder and conduct problems. Psychiatry Investig 10(3): 253-258.
13. Gulisano M, Domini C, Capelli M, Pellico A, Rizzo R (2017) Importance of neuropsychiatric evaluation in children with primary monosymptomatic enuresis. J Pediatr Urol 13(1): 1-36.

14. Achenbach TN (1990) Manual for the child behavior checklist/4e18 and 1991 profile. Burlington, University of Vermont, USA.

15. Esposito M, Gallai B, Parisi L, Roccella M, Marotta R, et al. (2013) Visuomotor competencies and primary monosymptomatic nocturnal enuresis in prepubertal aged children. Neuropsychiatr Dis Treat 9: 921926

16. Lei D, Ma J, Shen X, Du X, Shen G, et al. (2012) Changes in the brain microstructure of children with primary monosymptomatic nocturnal enuresis: a diffusion tensor imaging study. PLoS One 7(2): 310-323.

17. Joinson C, Grzeda MT, von Gontard A, Heron J (2018) A prospective cohort study of biopsychosocial factors associated with childhood urinary incontinence. Eur Child Adolesc Psychiatry.

18. Joinson C, Sullivan S, von Gontard A, Heron J (2016) Early childhood psychological factors and risk for bedwetting at school age in a UK cohort. Eur Child Adolesc Psychiatry 25(5): 519-528.

19. Jarvelin MR, Moilanen I, Vikevainen-Tervonen L, Huttunen NP (1990) Life changes and protective capacities in enuretic and non-enuretic children. J Child Psychol Psychiatry 31(5): 763-774.

20. Neveus T, Eggert P, Evans J, Macedo A, Rittig S, et al. (2010) Evaluation of and treatment for monosymptomatic enuresis: a standardization document from the International Children's Continence Society. J Urol 183(2): 441-447.

21. Aikawa T, Kasahara T, Uchiyama M (1998) The arginine-vasopressin section profile of children with primary nighttime enuresis. Eur Urol 33(3): 41-44.

22. Rittig S, Knudsen UB, Norgaard JP, Pedersen EB, Djurhuus JC (1990) Abnormal diurnal rhythm of plasma vasopressin and urinary output in patients with enuresis. Am J Physiol 256(4 Pt 2): F664-F671.

23. Yeung CK, Sihoe JD, Sit FK, Bower W, Sreedhar B, et al. (2004) Characteristics of primary nocturnal enuresis in adults: an epidemiological study. BJU Int 93(3): 341-345.

24. Grzeda M, Heron J, von Gontard A, Joinson C (2017) Effects of urinary incontinence on psychosocial outcomes in adolescence. Eur Child Adolesc Psychiatry 26(6): 649-658.

25. Glazener CMA, Evans JHC, Peto RE (2005) Alarm interventions for nocturnal enuresis in children. Cochrane Database of Systematic Reviews Issue 2: CD002911.

26. Glazener CMA, Evans JHC (2002) Desmopressin for nocturnal enuresis in children. Cochrane Database of Systematic Reviews.

27. Fagundes SN, Lebl AS, Azevedo Soster L, Sousa E Silva GJ, Silvares EF, et al. (2017) Monosymptomatic nocturnal enuresis in pediatric patients: multidisciplinary assessment and effects of therapeutic intervention. Pediatr Nephrol 32(5): 843-851.

28. Equit M, Hill J, Hubner A, von Gontard A (2014) Health-related quality of life and treatment effects on children with functional incontinence, and their parents. J Pediatr Urol 10(5): 922-928.

29. Sousa E Silva GJ, Sammour SNF, Ferraro AA, Koch VHK (2018) Study of the profile of behavioral problems and quality of life indexes in a pediatric cohort of monosymptomatic enuresis. J Pediatr (Rio J): S00217557(17)30548-X. 